\title{
Oversnow Traverses Aimed at Understanding Recent Change in the Climate and Atmospheric Chemistry Over Antarctica
}

\author{
Durham, New Hampshire, USA, 19-23 April, 1999
}

Glaciologists, geophysicists, remote sensing specialists and meteorologists from fifteen countries met to discuss the International Trans Antarctic Scientific Expedition (ITASE). ITASE is investigating the last $\sim 200$ years of change in climate and atmospheric chemistry over the Antarctic ice sheet (Mayewski and Goodwin, PAGES Workshop Report 97-1). It is jointly sponsored by the Group of Specialists on Global Change and the Antarctic (GLOCHANT) of the Scientific Committee on Antarctic Research (SCAR) and PAGES.

The available Antarctic meteorological data (re-analysis fields, in-situ observations, operational model fields) provide approximate descriptions of spatial and temporal variability of Antarctic accumulation and associated atmospheric circulation from approximately 1980 to date. Progress has been made in describing the impact of the seasonal cycle, semi-annual oscillation and ENSO cycle on Antarctic accumulation over this time period. Difficulties still remain in explaining fully the history and forcing of Antarctic climate and the links between tropical forcing and high latitude response. These difficulties arise largely because of the relatively short duration and sparse spatial coverage of Antarctic meteorological data.

By combining available meteorological data from the Antarctic and Southern Ocean with ice core proxies for a variety of climate parameters (e.g., moisture balance, atmospheric circulation and temperature) ITASE plans to extend the Antarctic climate record back $\sim 200$ years. This coverage offers the temporal perspective needed to assess the multi-decadal state of natural climate variability in Antarctic climate. In the process ITASE will be able to contribute to understanding the impact of global change on the Antarctic continent and the influence of Antarctica on global change. Examples of some of the issues treated at the meeting follow:

\section{Annual layer dating of ice cores and absolute dating through unique strati- graphic markers}

Development of annually resolved ice core series is recognized as an essential component of the ITASE program because of the fidelty needed for comparison and calibration with instrumental series. Several dating tools are used in dating ITASE cores. These include annual layer counting of stable isotope, chemistry and particle series. These annual layer counting tools are calibrated to volcanic and nuclear fall-out markers. As an example, sulfate from a variety of well documented volcanic emissions, covering the last 200 years, is potentially documented in Antarctic ice cores. These events include: Lascar, Chile (1993), Pinatubo, Philippines and Cerro Hudson, Chile (1991), El Chichón, Mexico (1982), Deception Island, South Shetlands (1972, 1969, 1967), Agung, Indonesia (1963), Cerro Azul, Argentina (1932), Santa Maria, Guatemala (1902), Tarawera, New Zealand (1886), Krakatau, Indonesia (1883), Coseguina, Nicaragua (1835), Babuyan, Philippines (1831), Galunggung, Indonesia (1822), Tambora, Indonesia (1815) and Unknown (1809).

\section{Ice core proxies for Antarctic moisture flux}

A selection of twenty three ice-core-derived accumulation rate time series, distributed around the continent, were compared during the workshop. Empirical orthogonal function analysis (EOF) of the series demonstrates that within regions the series share significant common variance. Investigation into associations between regions may provide evidence of the history of moisture bearing atmospheric circulation systems potentially associated with features in the ENSO system and the Antarctic Circumpolar Wave.

\section{Ice core proxies for major Antarctic atmospheric circulation patterns}

Recent instrumental linkages between the tropical ENSO system and the high southern latitudes demonstrate the ex- istence of an ENSO-Antarctic climatic teleconnection. These investigations reveal that annual temperatures at South Pole are positively correlated to annual values of the Southern Oscillation Index (SOI) of the previous year (Savage et al., 1988). The ENSO signal has been interpreted at South Pole in an ice core covering the time period 1922-1984 AD, and also in a core from Dronning Maud Land. They clearly show increases in Marine Sulfate Aerosol (MSA) concentration during El Niño events identified in the Quinn et al. (1987) historical El Niño chronology. MSA is produced from the oxidation of atmospheric dimethylsulfide (DMS), a major emission of marine phytoplankton. A new record from South Pole was presented at the meeting. This core extends the South Pole ice core proxy for ENSO back to AD 1500 and also identifies a sea ice MSA association previously observed at a site to the north on the Newall Glacier, southern Victoria Land. Background values of MSA in the South Pole core are associated with sea ice extent anomalies $\left(185^{\circ}-245^{\circ} \mathrm{E}\right)$ and outliers in MSA are associated with warm events (El Niño events) allowing investigation of ENSO-sea ice associations. A seasalt proxy for the strength of the Amundsen Sea Low developed from the Siple Dome ice core was also presented at the meeting.

\section{Ice core proxies for temperature and borehole temperature measurments}

Stable isotope measurements of ice $(\delta \mathrm{D}$, $\delta^{18} \mathrm{O}$ and deuterium excess) have classically been employed as a proxy for temperature in Antarctica and more recently borehole measurements have been undertaken to provide direct measures of snow surface temperature times series. An overview of results from these studies was presented at the meeting. Combined with instrumental observations, these results reveal an $\sim 1^{\circ} \mathrm{C}$ warming in the Antarctic Peninsula and Dronning Maud Land over the past few decades. High resolution ice cores on Law Dome, Wilkes Land have enabled the discrimination of seasonal 
stable isotope signals which are being calibrated to the instrumental meteorological record. This calibration is being used to resolve major precipitation events and temperature fluctuations.

\section{Examination of the ice sheet record between ice core sites}

Ice cores can provide annually resolved records of environmental change but they are based on centimeter scale diameter samples. Snow and ice radar systems on the other hand provide detailed information that can be tuned to investigate snow layering in the upper several tens of meters of the Antarctic ice sheet and down to thousands of meters in depth to detect ice thickness and bedrock configuration. Radar measurements between and around ice core sites add information that is extremely valuable in assessing the representativeness of ice core sites and in the determination of decadally averaged snow layer thicknesses between core sites. Detailed examination of changes in topography and ice dynamics that exert controls on accumulation rate are being conducted through GPS surveys along ITASE traverse routes in order to remove the influence of these factors and more clearly assess the influence of climate change on accumulation.

\section{Ground truth for satellite remote sensing of the Antarctic ice sheet}

Recent advances in remote sensing technology and availability of images has vastly improved traverse route selections, core site selection and spatial interpolation of ice core time series. As an example, temporal changes in snow surface elevation and velocity can be mapped using laser altimetry and interferometric methods. ITASE traverses provide unique opportunities for developing ground truthing for remote sensing experiments that are geared toward characterizing and interpreting changes in surface topography, surface temperature, surface velocity and various other surface characteristics of ice sheets (roughness, grain size, albedo).

\section{Future of ITASE}

The workshop also provided a venue for discussing the coordination of sample collection, sample handling, data exchange, data interpretation and future ITASE oversnow traverse plans for the next decade. ITASE efforts over the next decade are widely dispersed over the continent. Themes to be investigated by current and future ITASE investigations include:

(1) Relationship between Antarctic precipitation variability and ENSO associated climate, particularly, precipitation variability in Southern Australia and perhaps South America.

(2) Variations in cyclogenesis, storm tracks, moisture flux and the strength of the low pressure cells that surround Antarctica.

(3) Interannual and decadal variability in sea ice extent and concentration,

\section{Conference on Marine Environment: the Past, Present and Future}

\section{KaOhsiung, Taiwan, 26-28 January, 1999}

The Conference on Marine Environment: the Past, Present and Future was the result of a series of consultations with a number of international scientific organizations (JGOFS, LOICZ, PAGES and START) as well as individual scientists. It was hoped that such a conference would provide a forum that would result in lucid, candid descriptions of the status of the marine environment. Further, experiences learned from past environmental changes were deemed useful in order to ameliorate the fast growing environmental ills that face the oceans today.

The conference was organized into several themes each with two or more sessions related to JGOFS, LOICZ and PAGES. Four sessions were devoted to the "Marine Environment, the Past" with 16 oral presentations and 4 posters. These were mostly related to the Western Pacific Warm Pool. For example, the warm pool in the eastern Indian Ocean during the last 30,000 years was discussed by P. de Deckker, during the last glacial maximum by R.J.I. Martinez, and in the Sulu Sea over the past 140 kyr by B.K. Linsley. H. Kawahata reported on the fluctuations in material transport during the late Pleistocene, and E. Matsumoto reconstructed the climate patterns of recent centuries in the Kuroshio region on the basis of corals. persistence and maintenance of coastal 'latent heat' polynyas.

(4) Changes in the chemistry of the atmosphere over Antarctica and differentiation of natural versus anthropogenic controls on such change.

Working group reports from the meeting, related references, descriptions of the research presented and the ITASE Science and Implementation Plan (Mayewski and Goodwin, 1997) are available at www.antcrc.utas.edu.au/scar/ itase.html.

\section{Paul Mayewski}

University of New Hampshire, Durham NH, USA paul_mayewski@grg.sr.unh.edu
M. Yoshino reported on paleomonsoon circulation in East Asia in the period of 18,000-20,000 B.P. M.Y. Oba described surface temperature off the eastern coast of Japan during the last glacial maximum.

The second major topic centered on the South China Sea. K.Y. Wei, M.T. Chen, T.Q. Lee, C.Y. Huang, E.F. Yu and L.W. Wang discussed such areas as paleotemperature, paleomonsoon and paleoproductivity, mostly based on IMAGES cores. G.J. Wei spoke about Mg/ $\mathrm{Ca}$ and $\mathrm{Sr} / \mathrm{Ca}$ coral thermometry. H.C. Lan compared the paleomonsoon records of Inner Mongolia and the South China Sea. On a larger scale Y. Ono presented the synchronicity of rapid climatic changes in Monsoon Asia. J.D. Ortiz presented the application of non-invasive methods to sediments collected from Western Pacific marginal seas. S.R. Troelstra introduced a global perspective of the conveyor belt. Finally, Z.X. Liu reported on Quaternary seismic stratigraphy in the East China Sea shelf, and Y.C. Chen discussed coccolith in the ocean environment.

After these presentations a special Workshop on the Western Pacific Margins was organized by M.T. Chen and P. de Deckker. The working group was initiated and approved in the IMAGES 